\title{
Intradialytic Exercise on Changes in Blood Pressure in Chronic Kidney Failure Patients during Hemodialysis Therapy
}

\author{
Wahyu Rima Agustin*(D), Wahyuningsih SafitriD, Dyan Kurniasari, Setiyawan Setiyawan, Atiek Murharyati, Rufaida Nur Fitriana \\ Department of Nursing, Kusuma Husada University of Surakarta, Surakarta City, Indonesia
}

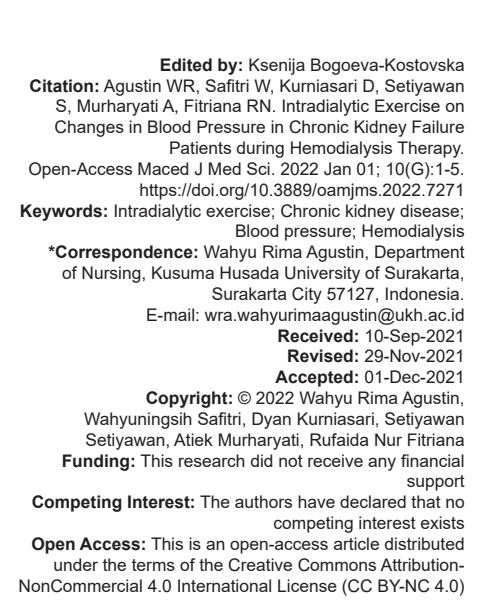

\begin{abstract}
BACKGROUND: Chronic kidney disease (CKD) is a chronic decline in kidney function that causes irreversible and progressive kidney tissue damage. Blood pressure is a major factor that can cause death up to 20 times in CKD patients undergoing hemodialysis therapy.

AIM: This study aims to analyze the effect of intradialytic exercise that will benefit the cardiovascular system on changes in blood pressure in CKD patients undergoing hemodialysis therapy.

METHODS: The research method used is a quasi-experimental pre-post design with a control group design. The study population was 97 dialysis patients. The sampling technique used purposive sampling as many as 30 people. Inclusion criteria: Patients with systolic blood pressure not $>180 \mathrm{mmHg}$ and diastolic $120 \mathrm{mmHg}$ were included in the study, exclusion criteria: Patients with comorbidities, namely, asthma and heart disease were excluded from the study. Data analysis using paired t-test.

RESULTS: The results showed that the average blood pressure in the control group, before exercise was: Systolic $168.93 \mathrm{mmHg}$, diastolic $106.20 \mathrm{mmHg}$, after exercise: Systolic $173.13 \mathrm{mmHg}$, diastolic $107 \mathrm{mmHg}$. The results of the average blood pressure in the intervention group, before exercise was: Systolic $162.20 \mathrm{mmHg}$, diastolic 104.27 $\mathrm{mmHg}$, after exercise: Systolic $153.13 \mathrm{mmHg}$, diastolic $94.33 \mathrm{mmHg}$.

CONCLUSION: The $p$ value in the control group was found to be 0.321 or $p>0.05$, while in the intervention group, $p=0.025$ or $p<0.05$. Intradialytic exercise can lower blood pressure in CKD patients undergoing hemodialysis therapy.
\end{abstract}

\section{Introduction}

Chronic kidney disease (CKD) is an important epidemic and public health problem which occurs in many countries with an increasing prevalence. Over 50 million people throughout the world are known to have CKD, more than 1 million require renal replacement therapies such as dialysis and renal transplantation. In recent years, the rising incidence of diabetes and hypertension, the most common two causes of CKD, has caused an increase in the prevalence of CKD [1]. Impaired kidney function occurs when the body fails to maintain metabolism and balance of fluids and electrolytes, causing retention of urea and other nitrogen residues in the blood. Kidney damage can result in problems with the ability and strength of the body which causes disruption of work activities, the body becomes easily tired and weak so that the patient's quality of life decreases. The WHO stated that the growth of people with kidney failure in 2013 had increased by $50 \%$ from the previous year. The prevalence of chronic renal failure who underwent dialysis was $19.3 \%$ in 2018 . The number of people with kidney failure in Indonesia is around 150 thousand people and 10 thousand people undergoing hemodialysis [2].
Hemodialysis is a process of kidney replacement therapy using a semi-permeable membrane that functions like a nephron so that it can remove metabolic waste products and correct fluid and electrolyte balance disorders in patients with renal failure. Hemodialysis performed by the patient can maintain survival while changing the patient's lifestyle [3].

Hypertension and chronic renal failure are closely related. Based on the results of the study, the etiology of chronic kidney failure was mostly dominated by hypertension, around $71.7 \%$. Hypertension can be a cause of renal failure and conversely, kidney disease can cause hypertension through sodium and fluid retention mechanisms [4]. Blood pressure is a major risk factor for cardiovascular disease with up to 20-fold increased mortality in patients with chronic renal failure undergoing hemodialysis. The condition of patients undergoing hemodialysis therapy will trigger various problems such as physical, psychological, lifestyle, and social changes that will have an impact on the patient's quality of life. Correct understanding of the mechanisms involving intradialytic changes in blood pressure can lead to the choice of good management [5].

In 2018, the hemodialysis unit at the Indriati Solo Baru Hospital had 20 hemodialysis machines 
for CKD patients, with a therapy delivery system divided into two shifts, morning and afternoon, each CKD patient was scheduled 2 times a week with a frequency of $10 \mathrm{~h} /$ week. During the hemodialysis process, the patient experienced complications with intradialytic hypertension. Intradialytic hypertension is a complication that often occurs and is not adequately controlled. The results of the examination of 10 hemodialysis patients experienced problems in blood pressure, namely, that all of them experienced an increase in blood pressure, making the patient even more anxious about their condition. The nurse takes action to reduce patient anxiety by encouraging the family to always accompany the story so that it can reduce the patient's anxiety, encouraging the patient to distract by watching TV, and the nurse providing the education needed to reduce this anxiety. Intradialytic exercise is one of the preferred and safe intervention methods to control the reduction of systolic blood pressure (SBP) because it can increase patient comfort for hemodialysis therapy [6].

Based on this background, the aim of the study was to analyze the effect of intradialytic exercise on changes in blood pressure in chronic renal failure patients undergoing hemodialysis therapy in the hemodialysis room of Indriati Solo Baru Hospital.

\section{Materials and Methods}

This type of research is quantitative with a quasi-experimental pre-post design with a control group design. The population in this study was 97 dialysis patients in the hemodialysis room of Indriati Solo Baru Hospital. The sampling technique used the purposive sampling method of 30 respondents. The inclusion criteria in this study are as follows:

1. Patients who undergo routine dialysis at Indriati Solo Baru Hospital twice a week

2. Patients who are able to follow intradialytic exercise

3. Patients with SBP not $>180 \mathrm{mmHg}$ and diastolic $>120 \mathrm{mmHg}$ (because if their blood pressure exceeds these limits, they will receive antihypertensive drugs, so they cannot be taken as research respondents).

The exclusion criteria in this study are as follows:

1. Patients with comorbidities, namely, asthma and heart disease

2. Patients who did not complete intradialysis exercise in any of the sessions (warm-up session, core session, and cool down session).

The research was conducted in the hemodialysis room of the Indriati Solo Baru Hospital from February
2019 to April 2019. The research was conducted in the hemodialysis room of the Indriati Solo Baru Hospital from February 2019 to April 2019, after determining the control and intervention group respondents. Then, the data were collected before the intradialytic exercise intervention, the respondents were given an explanation about the intradialytic exercise which was carried out every time they carried out hemodialysis therapy 2 times a week, carried out for $30-45 \mathrm{~min}$ at the $1^{\text {st }}$ and $2^{\text {nd }} \mathrm{h}$ after the installation of vascular access, and carried out for 8 weeks. Within 8 weeks after the intervention, data were taken on the control and intervention groups. The research tool used an intradialytic SOP exercise; blood pressure assessment sheets; and leaflet intradialytic exercises for patient education. Analysis of the data used to determine the relationship between the two variables using the paired t-test.

Before the data were carried out the paired t-test, the research data were tested for normality and homogeneity of the data to meet the requirements of the paired t-test parametric test. The data normality test uses the Shapiro-Wilk test because the number of data is $<50$ respondents while the data homogeneity test uses Levene's, it is known that the $p$ value in each group is $p>0.05$, meaning that the research data are homogeneous.

Furthermore, the probability value (sig.) if $p<0.05$, then $H_{0}$ is rejected and $H_{1}$ is accepted, which means that there is a significant influence between the pre and post averages and if $p>0.05$, then $H_{0}$ is accepted and $\mathrm{H}_{1}$ is rejected, meaning that there is no the effect of intradialysis exercise on changes in blood pressure in patients with chronic renal failure undergoing hemodialysis therapy in the hemodialysis room of Indriati Hospital Solo Baru.

\section{Results}

\section{Characteristics of respondents}

Characteristics of respondents based on gender in Table 1 show that the majority of respondents were male as many as 17 people (56.7\%).

Table 1: Characteristics of respondents by gender $=\mathbf{3 0}$

\begin{tabular}{|c|c|c|c|c|c|c|}
\hline \multirow[t]{2}{*}{ Gender } & \multicolumn{2}{|c|}{ Control } & \multicolumn{2}{|c|}{ Intervention } & \multicolumn{2}{|c|}{ Total } \\
\hline & $f$ & $\%$ & $f$ & $\%$ & $f$ & $\%$ \\
\hline Male & 7 & 46.6 & 10 & 66.6 & 17 & 56.7 \\
\hline Female & 8 & 53.4 & 5 & 33.4 & 13 & 43.3 \\
\hline Total & 15 & 100 & 15 & 100 & 30 & 100 \\
\hline
\end{tabular}

The characteristics of respondents based on age in Table 2 indicate that the minimum age of the respondent is 29 years and the maximum age is 72 years.

Table 2: Characteristics of respondents by age $(n=30)$

\begin{tabular}{llll}
\hline Category & Minimum (year) & Maximum (year) & Mean (year) \\
\hline Age & 29 & 72 & 51,03 \\
\hline
\end{tabular}




\section{Respondents blood pressure measurement}

Based on the results of the paired t-test, it is known that $p=0.321$ or $p>0.05$ was considered in the control group while in the treatment group, $p=0.025$ or $p<0.05$ was considered, so there is an effect of intradialytic exercise on changes in blood pressure in patients with chronic kidney failure undergoing hemodialysis therapy at home Indriati Solo Baru Hospital.

\section{Discussion}

Characteristics of respondents based on gender based on Table 1 show that the largest number of respondents was 17 males (56.7\%).

The large proportion of CKD patients undergoing hemodialysis therapy is due to an increase in creatinine which is influenced by muscle mass or rhabdomyolysis. Men tend to have more muscle mass so blood creatinine levels are higher than men. The results of other studies showed that the proportion of CKD who underwent hemodialysis therapy was male $68.3 \%$ and female $31.7 \%$ although some literature explained that CKD patients were not influenced by gender, meaning that men and women had the same risk of developing CKD [7].

The prevalence rate of CKD in men is thought to be related to the type of supplement consumed because in general, men are more and often consume food and drinks or supplement drugs for a relatively long time. These foods and drinks and supplements have a side effect of CKD. Patients who consume supplement drinks are more at risk of developing kidney failure because the sugar content in supplement drinks is about $25 \mathrm{~g}$ in every $150 \mathrm{ml}$ bottle [8].

CKD is defined as the presence of kidney damage or an estimated glomerular filtration rate (eGFR) less than $60 \mathrm{~mL} / \mathrm{min} / 1.73 \mathrm{~m}^{2}$, persisting for 3 months or more, irrespective of the cause. It is a state of progressive loss of kidney function ultimately resulting in the need for renal replacement therapy with dialysis or transplantation. Kidney damage refers to pathologic abnormalities either suggested by imaging studies or renal biopsy, abnormalities in urinary sediment, or increased urinary albumin excretion rates [9].

There are various factors that can affect the quality of life of patients with CKD undergoing hemodialysis, namely, sociodemographic factors such as gender, age, education level, marital status, employment status or economic status, and nutrition or diet related to nutritional intake. Other factors are depression, presence of comorbidities or comorbidities, length of time on hemodialysis, non-adherence to treatment, high body mass index, social support, adequate hemodialysis, and interdialytic weight gain, urine output, and hemoglobin values [10]. The results of Masi and Kundre's, 2018, study [11] showed a comparison of quality of life between chronic renal failure patients with comorbid hypertension and diabetes mellitus.

Based on Table 2, the overall average of respondents is 51.03 years old. The incidence of CKD is also related to the level of infection in the kidney organs, namely, CKD and a person's lifestyle such as DM and hypertension, and age. The older a person is, the higher the risk of developing CKD because the kidneys experience a decline in function and performance, which, in turn, are unable to compensate, causing kidney failure. The results of Pranandari and Woro's study [12] showed that most of the respondents with CKD were in the age range 26-55 years, as much as $58.5 \%$. Physiologically, at the age of $40-70$ years, the glomerular filtration rate will decrease progressively to $50 \%$ of normal, resulting in a decrease in the ability of the renal tubules to reabsorb and concentrate urine. Decreased ability to completely empty the bladder increases the risk of obstructive infection and decreased fluid intake, which is a risk factor for kidney damage. As you get older, the kidney function decreases, namely, the decrease in glomerular excretion rate and deterioration of tubular function. Decrease in kidney function on a small scale is a normal process for every human being as we get older, but it does not cause abnormalities or cause symptoms because it is still within reasonable limits that the kidneys and the body can tolerate. However, due to the presence of several risk factors for kidney abnormalities, there will be a rapid or progressive decline in kidney function, causing various complaints from mild to severe, this condition is called CKD [13].

CKD is defined as the presence of kidney damage, manifested by abnormal albumin excretion or decreased kidney function, quantified by measured, or estimated GFR that persists for more than 3 months [14]. In CKD, the GFR value falls below normal by $125 \mathrm{~mL} / \mathrm{min}$. Decreased GFR (Glomerular Filtration Rate) according to age, that at the age of over 30 years will experience a decrease in GFR values at a rate of about $1 \mathrm{~mL} /$ minute/year [15]. If there is damage to the number of nephrons after birth, it cannot be formed again. After the age of 40 years, the number of nephrons generally decreases by $10 \%$ every 10 years so that by the age of 80 , the number of nephrons is reduced by $40 \%$ compared to the age of 40 years [16].

CKD defined as a persistent abnormality in kidney structure or function, for example, GFR $<60 \mathrm{~mL} / \mathrm{min} / 1.73 \mathrm{~m}^{2}$ or albuminuria $>30 \mathrm{mg} / 24 \mathrm{~h}$ for more than 3 months, CKD affects $8-16 \%$ of the population worldwide. In developed countries, CKD is most commonly attributed to diabetes and hypertension [17]. Diabetes and hypertension are the main causes of CKD in all high-income and 
middle-income countries, and also in many low-income countries. Incidence, prevalence, and progression of CKD also vary within countries by ethnicity and social determinants of health, possibly through epigenetic influence [1]. DM is a comorbid factor that can affect the condition of CKD patients because high blood sugar levels can interfere with the structure and function of blood vessels. Patients with diabetes mellitus have low insulin levels, causing disturbances in the metabolism of carbohydrates, fats, and proteins in the body related to impaired permeability of blood vessels in the kidneys so that they will be damaged.

The results of measuring respondents' blood pressure before and after treatment according to Table 3 show that in the control group, the mean preSBP was $168.93 \mathrm{mmHg}$ and diastolic $106.20 \mathrm{mmHg}$, while post-SBP was $173.13 \mathrm{mmHg}$ and diastolic $107 \mathrm{mmHg}$. Initial blood pressure was taken in the $1^{\text {st }}$ week the patient agreed to be a respondent in the study, while post data were taken at week 8 without any treatment. Standard therapy from hospital patients who experience SBP> $180 \mathrm{mmHg}$ will be given routine antihypertensive drugs, namely, amlodipine $1 \mathrm{mg} \times$ $10 \mathrm{mg}$. According to researchers, hemodialysis is a method to remove excess fluid and toxins when the patient's blood circulates through the artificial kidney (dialyzer) and the kidneys help maintain blood pressure by excreting or storing sodium and water. When blood pressure drops, the kidneys start the renin-angiotensin mechanism. The renin-angiotensin mechanism stimulates vasoconstriction, which causes the release of the hormone aldosterone from intradialytic exercises including various stages of flexibility exercise, strengthening exercise, and cardiovascular exercise performed during hemodialysis to improve the blood circulation system. Intradialytic exercise is performed in the first $1-2 \mathrm{~h}$ of hemodialysis for $30-45 \mathrm{~min}$ and can be started after the vascular access insertion is complete. Hemodialysis measures can prevent cardiac decompensation that can occur if intradialytic exercise is performed after $2 \mathrm{~h}$ of hemodialysis therapy. In exercise, there are many physiological changes that occur as a result of the adaptation process of various systems in the body. The adaptation to exercise in the body system will show many physical and biochemical changes in the blood, cardiovascular, respiratory, and muscular vascular systems.

Table 3: Blood pressure measurements in the control and treatment groups $(n=30)$

\begin{tabular}{|c|c|c|c|c|c|c|c|}
\hline \multirow[t]{2}{*}{ Category } & \multicolumn{3}{|l|}{ Pre } & \multicolumn{3}{|l|}{ Post } & \multirow[t]{2}{*}{ Sig. } \\
\hline & Minimum & Maximum & Mean & Minimum & Maximum & Mean & \\
\hline \multicolumn{8}{|l|}{ Control } \\
\hline Systole & 152 & 180 & 168,93 & 159 & 187 & 173,13 & 0,321 \\
\hline Diastole & 92 & 120 & 106,20 & 91 & 119 & 107 & \\
\hline \multicolumn{8}{|l|}{ Intervention } \\
\hline Systole & 139 & 180 & 162,2 & 139 & 169 & 153,13 & 0,025 \\
\hline Diastole & 90 & 118 & 104,27 & 82 & 115 & 94,93 & \\
\hline
\end{tabular}

This shows that intradialytic exercise in the form of regular physical exercise during intrahemodialysis can increase blood flow to the muscles, increase the number of capillaries, and increase the area and surface of the capillaries, thereby increasing the movement of urea and toxins from the tissues to the vascular, which are then flowed to the dialyzer. According to researchers, intradialytic exercise can be perceived to be the same as physical exercise which will have a good effect on various organ systems in the body, one of which is the cardiovascular system, wherewith proper and regular physical exercise, the work efficiency of the heart will occur. The work efficiency of the heart or the heart's ability will increase according to the changes that occur. This can include changes in heart rate and cardiac output.

Physical exercise elicits potential antiinflammatory effects that are likely to account for many of the salutary actions of regular exercise on chronic metabolic diseases [18]. A lack of physical activity is linked to the development of many chronic diseases. It is now well established that the immune system and inflammation play a central role in the development of numerous chronic metabolic diseases. Intradialytic exercise can reduce fatigue in patients undergoing hemodialysis [19]. Planned physical exercise has four basic components, namely, muscle strength, muscle endurance, flexibility, and cardiorespiratory endurance. The effect of exercise will provide physiological changes that occur in almost every system of the body. Changes will be achieved when sufficient time is required for physiological adaptation, which is in the range of 6-8 weeks. The condition of a decrease in blood pressure because the blood vessels experience dilation and relaxation. Overtime, exercise can relax blood vessels so that blood pressure decreases, just as a widening of a water pipe lowers water pressure. In this case, exercise can reduce peripheral resistance. A decrease in blood pressure can also occur due to reduced pumping activity of the heart. The heart muscle in people who regularly exercise is very strong, so the heart muscle in that individual contracts less than the heart muscle in individuals who rarely exercise to pump the same volume of blood [20]. A simplified aerobic exercise program has increased the efficacy of dialysis and may be considered as a safe, complementary, and effective modality for hemodialysis patients [21]. Thus, exercise will reduce cardiac output, which, in turn, causes a drop in blood pressure. An increase in the work efficiency of the heart is reflected in a decrease in systolic pressure, while a decrease in peripheral resistance is reflected in a decrease in diastolic pressure. Intradialytic exercise can be recommended as structured physical exercise therapy for hemodialysis therapy patients. The need for further research on intradialytic exercise combined with other methods. 


\section{Conclusion}

There is an effect of intradialytic exercise on changes in blood pressure in chronic renal failure patients undergoing hemodialysis therapy at Indriati Solo Baru Hospital with $p=0.025$.

\section{Acknowledgments}

The researcher is grateful to the Center for Research and Community Service of Kusuma Husada University of Surakarta.

\section{References}

1. Webster AC, Nagler EV, Morton RL, Masson P. Chronic kidney disease. Lancet. 2017;389(10075):1238-52. https://doi. org/10.1016/S0140-6736(16)32064-5

PMid:27887750

2. Riskesdas. Basic Health Research Results of the Ministry of Health of the Republic of Indonesia; 2018. Available from: http://www.depkes.go.id/resources/download/general/hasil\%20 riskesdas\%2018.pdf. [Last accessed on 2019 Jul 18].

3. Ignatavicius D, Workman ML. Medical Surgical Nursing: PatientCentered Collaborative Care. United States America: Sounders, Elsevier; 2009.

4. Price SA, Wilson LM. Pathophysiology Clinical Concepts of Disease Processes. Jakarta: Medical Book Publishers EGC; 2005.

5. KDIGO (Kidney Disease Improving Global Outcomes). Clinical practice guideline for the evaluation and management of chronic kidney disease. Kidney Int Suppl. 2013;3:1-150. https://doi. org/10.1016/j.kisu.2017.10.001

6. Jung TD, Park SH. Intradialytic exercise programs for hemodialysis patients. Chonnam Med J. 2011;47(2):61-5. https://doi.org/10.4068/cmj.2011.47.2.61 PMid:22111062

7. dan Asikin K. Description in the level of knowledge regarding kidney disease and renal diet therapy and quality of life among Hemodyalisis Patients in Dr. Ramelan Naval Hospital, Surabaya. Am Nutr. 2018;2(2):1

8. Nayana SA, Balasubramanian T, Nathaliya PM, Hussain PN, Salim KT, Lubab PM. A cross sectional study on assessment of health related quality of life among end stage renal disease patients undergoing hemodialysis. Clin Epidemiol Glob Health. 2017;5:148-53. https://doi.org/10.1016/j.cegh.2016.08.005

9. Vaidya SR, Aeddula NR, Doerr C. Chronic renal failure (nursing). In: Stat Pearls. Treasure Island, FL: Stat Pearls Publishing; 2021. PMid:33760537

10. Mailani F. Quality of life for chronic kidney disease patients underwent hemodialysis: Systematic: Review. Nurse J Nurs. 2015;11(1):1-8.

11. Masi GN, Kundre R. Comparison of the quality of life of patients with chronic renal failure with comorbid factors of diabetes mellitus and hypertension in the Hemodialysis room, Prof. Dr. R.D. Kandou Manado. E J Nurs. 2017;5(2):1-9. Available from: https://www.ejournal.unsrat.ac.id/index.php/jkp/article/ view/25163. [Last accessed on 2019 Jul 18].

12. Pranandari R, Woro $S$. Risk factors for chronic renal failure in the hemodialysis unit of wates Kulon Progo hospital. Pharm Mag. 2015;1(2):316-20.

13. Brunner, Suddarth. Textbook of Medical Surgical Nursing. $8^{\text {th }}$ ed. Jakarta: ECG Medicine; 2013.

14. Thomas R, Kanso A, Sedor JR. Chronic kidney disease and its complications. Prim Care. 2008;35(2):329-44, 7. https://doi. org/10.1016/j.pop.2008.01.008 PMid: 18486718

15. Potter PA, Perry AG. Nursing Fundamentals Textbook: Concepts, Process and Practice. $4^{\text {th }}$ ed. Jakarta: EGC; 2010.

16. Guyton, AC, Hall, JE. Textbook of Medical Physiology. 11th ed. Book Medical Publishers EGC; 2008.

17. ChenTK,KnicelyDH, GramsME. Chronickidneydiseasediagnosis and management: A review. JAMA. 2019;322(13):1294-304. https://doi.org/10.1001/jama.2019.14745 PMid:31573641

18. Lancaster GI, Febbraio MA. The immunomodulating role of exercise in metabolic disease. Trends Immunol. 2014;35(6):262-9. https://doi.org/10.1016/j.it.2014.02.008 PMid:24680647

19. Liao MT, Liu WC, Lin FH, Huang CF, Chen SY, Liu CC, et al Intradialytic aerobic cycling exercise alleviates inflammation and improves endothelial progenitor cell count and bone density in hemodialysis patients. Medicine (Baltimore). 2016;95(27):e4134. https://doi.org/10.1097/MD.0000000000004134 PMid:27399127

20. Ouzouni S, Kouidi E, Sioulis A, Grekas D, Deligiannis A Effects of intradialytic exercise training on health-related quality of life indices in haemodialysis patients. Clin Rehabil. 2009;23(1):53-63. https://doi.org/10.1177/0269215508096760 PMid: 19114437

21. Mohseni R, Emami Zeydi A, Ilali E, Adib-Hajbaghery $M$, Makhlough A. The effect of intradialytic aerobic exercise on dialysis efficacy in hemodialysis patients: A randomized controlled trial. Oman Med J. 2013;28(5):345-9. https://doi. org/10.5001/omj.2013.99

PMid:24044062 